\title{
Intra-Serotype Polyprotein Variation and its Effect on Antigenicity of Dengue Virus
}

\author{
Ipsita Chanda', Archana Pan ${ }^{2}$, Pranavathiyani G ${ }^{3}$ \\ ${ }^{1}$ Department of Zoology, S.A. Jaipuria College, Kolkata, India. \\ ${ }^{2,3}$ Centre for Bioinformatics, Pondicherry University, Pondicherry, India. \\ DOI: https://doi.org/10.24321/0019.5138.202106
}

\section{I $\quad \mathbf{N} \quad \mathbf{F} \quad \mathbf{O}$}

\section{Corresponding Author:}

Ipsita Chanda, Department of Zoology, Seth Anandram Jaipuria College, Kolkata, West Bengal E-mail Id:

icsajc@gmail.com

Orcid Id:

https://orcid.org/0000-0002-0795-294X

How to cite this article:

Chanda I, Pan A, Pranavathiyani G. IntraSerotype Polyprotein Variation and its Effect on Antigenicity of Dengue Virus. J Commun Dis 2021; 53(1): 27-34.

Date of Submission: 2021-01-18

Date of Acceptance: 2021-03-20
$\begin{array}{llllllll}\mathbf{A} & \mathbf{B} & \mathbf{S} & \mathbf{T} & \mathbf{R} & \mathbf{A} & \mathbf{C} & \mathbf{T}\end{array}$

Dengue virus is a mosquito-borne human pathogen, causing disease that ranges from mild febrile illness to life-threatening hemorrhage fever/ shock syndrome. The altered antigenicity and virulence in the dengue virus, resulting from the accumulation and fixation of the favorable mutations in the genome, is the cause of concern nowadays. The present study focuses on the comparative study of polyproteins of viral strains within each dengue serotype to understand the trend of intra-serotype polyprotein variation and its effect on the antigenicity. Polyprotein sequences of viral strains in each serotype were investigated using multivariate statistical analysis, phylogenetic analysis and multiple sequence alignment methods. Epitope prediction was done by Bepipred-1.0 server and experimental epitope data were extracted from Immune Epitope Database with BLAST search. The study reveals that the polyproteins of viral strains of a serotype have variable amino acid composition that corresponds to the geographical regions of origin. This compositional variation has occurred due to the presence of polymorphic residues at different positions along the polyprotein sequence. The polymorphic residues have also been identified at epitope regions of structural proteins as well as NS1 of viral strains, possessing dissimilar physicochemical properties and occupy surface accessible positions. These positions on epitopes with polymorphic, dissimilar and surface accessible residues might act as putative sites for generation of antigenic variation among viral strains of a serotype of different geographical origin. Thus, these polymorphic residue positions on epitopes might be considered as putative target for development of drug or vaccine, in future.

Keywords: Dengue, Serotype, Polyprotein, Epitope, Polymorphic, Antigenic

\section{Introduction}

Dengue Virus (DENV) is an arthropod-borne viral pathogen in human mainly in tropical and subtropical regions of the world. ${ }^{1}$ The two important vectors for the endemic/ epidemic life cycle of the pathogen are Aedes albopictus and Aedes aegypti. About 2.5 billion people across 100 countries are at risk of being infected by DENV. ${ }^{2}$ Dengue diseases are mostly endemic in Africa, America, Eastern 
Mediterranean, South-East Asia and Western Pacific. ${ }^{3}$ DENV has a positive single stranded RNA. The genome has three structural genes encoding structural proteins like capsid (C), pre-membrane/membrane (prM/M) and envelop (E), and seven non-structural genes encoding NS1, NS2A, NS2B, NS3, NS4A, NS4B and NS5, flanked by $5^{\prime}$ and $3^{\prime}$ non-translated regions ( $5^{\prime}$ NTR/ $3^{\prime}$ NTR). The single open reading frame (ORF) of the genome is translated into single polyprotein comprising of approximately 3400 amino acids, which is post-translationally cleaved to produce the individual proteins. ${ }^{4}$ Dengue virus has four antigenically distinct serotypes, DENV-1 to DENV-4. Each serotype contains viral strains with genetic diversity, called genotypes. ${ }^{5}$ The human immune system produces both neutralizing and cross-reactive antibodies during infection by a particular serotype/ genotype of DENV. The neutralizing antibodies neutralize a serotype/genotype in a potent and type-specific manner. On the other hand, the cross-reactive antibodies enhance the severity of the disease during subsequent infection by another serotype/ genotype via a mechanism termed as Antibody-Dependent Enhancement (ADE) of the infection. ${ }^{6}$ Infection by dengue virus results in disease that ranges from mild acute febrile illness (DF) to life-threatening dengue hemorrhagic fever or dengue shock syndrome (DHF/ DSS). ${ }^{1}$ DENV has the tendency to accumulate mutations rather rapidly due to error-prone nature of RNA polymerase. The mutations which increase viral fitness are fixed in the genome. ${ }^{1}$ Such genetic changes might result in the emergence of new genotypes with altered antigenicity and virulence of the virus. ${ }^{1}$ Phylogenetic studies on the structural gene regions (E/NS1, C/prM/E or complete $E$ gene) of DENV serotypes have identified that genetic variations or genotypes correspond to the regions of geographic origin of viral strains. ${ }^{7-10}$ Also, the synonymous codon usage pattern has stronger correlation with geographic origin of the viral strains in each serotype. ${ }^{2}$ However, there was report that polyprotein architecture is highly conserved in DENV under stronger purifying selection. ${ }^{11}$ In this context, the present article focuses on the comparative study of polyproteins of viral strains in each dengue serotype to understand the trend of intra-serotype polyprotein variation and its effect on antigenicity of the viral strains.

\section{Materials and Methods}

\section{Genome Sequences}

About 4009 polyprotein coding sequences of DENV serotypes 1-4 were downloaded from NCBI Dengue virus database (http://www.ncbi.nlm.nih.gov/genomes/VirusVariation/ Database/nph-select.cgi?taxid=12637).

Each genome contains the sequence, annotation of location and year of isolation of the viral strain. The sequences with internal stop codons, untranslated codons and redundancy were eliminated from the genome dataset. After elimination, the final dataset contains about 2157 polyprotein coding sequences (896 of DENV-1, 671 of DENV2, 502 of DENV-3 and 88 of DENV-4). The corresponding polyprotein sequences were also downloaded from the database (collected data until December, 2018).

\section{Correspondence Analysis}

Correspondence Analysis (COA) ${ }^{12}$ is an efficient statistical method which depicts the relationship among multiple categorical variables. COA creates a series of orthogonal axes to identify trends that explains the data variation, with each subsequent axis explaining a decreasing amount of variation. COA on amino acid usage was used to identify the variation in amino acid composition within the polyproteins of viral strains in each DENV serotype, isolated from different countries during different time periods, with the help of the program CodonW 1.4.2. ${ }^{13}$

\section{Phylogenetic Analysis}

Phylogenetic analysis was performed to determine the lineage of viral strains, isolated from different countries during different time periods, in each dengue serotype. Multiple sequence alignment of the polyprotein sequences of viral strains in each serotype was carried out using ClustalW (with defaults parameters). ${ }^{14}$ Phylogenetic analysis was performed by neighbor joining algorithm and bootstrap analysis was carried out with 500 trials using MEGA program (Version 6). ${ }^{15}$

\section{Identification of Polymorphic Residue Variation}

Multiple sequence alignment of the polyprotein sequences of viral strains, isolated from different countries during different time periods, was performed for each serotype. The residue variations at any position of polyprotein sequence alignment that include at least $1 \%$ of the viral population in each serotype, were counted and considered as polymorphic residue variation. ${ }^{16,17}$ The polymorphic residues in each serotype were obtained using an in-house Perl script (https://tinyurl.com/DENV-program).

\section{Experimental Epitope Data Mining}

Epitopes at structural protein and NS1 regions of the polyprotein of viral strains in each serotype were predicted using Bepipred-1.0 Linear Epitope Prediction method ${ }^{18}$ with default threshold 0.35 , sensitivity 0.49 and specificity 0.75 . Surface accessibility of the residues was determined using Emini surface accessibility scale ${ }^{19}$ with the help of Antibody Epitope Prediction software-IEDB Analysis Resource. The Immune Epitope Database (IEDB) was utilized to retrieve experimental data of linear epitopes of viral strains in each dengue serotype with BLAST search (identity $\geq 70 \%$ ) by using predicted epitopes as query. 


\section{Results and Discussion}

\section{Polyprotein Composition}

Table 1, shows the mean frequencies (along with standard deviation) of different amino acid residues of complete polyprotein sequences of viral strains in each DENV serotype, isolated from different countries during different time periods. The residues are categorized as abundant, intermediate, rare and very rare based on their mean frequencies. It is observed that Leu, Val, Thr, Ala, Gly, Lys, Glu are abundant; lle, Ser, Pro, Asp, Arg are intermediate; Phe, Met, Tyr, Trp, His, Asn, Gln are rare and Cys is very rare amino acids in case of all four DENV serotypes. The reason for the abundance of residues like Leu, Val, Thr, Ala, Gly, Lys and Glu in all serotypes is not very clear. However, there are evidence that some of these abundant residues are associated with virus assembly and entry, infectivity and pathogenicity. ${ }^{4,20-22}$

\section{Trend of Variation of Polyproteins}

Table 1, explains that a set of residues have relatively higher standard deviation indicating the presence of variation in amino acid composition of the polyproteins of viral strains in each serotype. To find out the trend of variation, Correspondence analysis (COA) on amino acid usage was performed and the polyproteins of viral strains in each serotype were plotted within the first two principal axes generated by COA on amino acid usage (Figure 1). The figure illustrates that the polyproteins of viral strains, isolated from different countries of America, Asia and Oceania during different time periods, are displayed into distinct clusters within the axes in each serotype. This indicates that polyproteins in a cluster have the similar amino acid composition and that differs from the polyproteins in other clusters. Thus, the polyproteins of viral strains in each serotype have variable amino acid composition.

Table I.Polyprotein composition of viral strains in dengue serotypes

\begin{tabular}{|c|c|c|c|c|c|c|c|c|}
\hline \multirow[b]{2}{*}{ Amino acids } & \multicolumn{2}{|c|}{ DENV-1 } & \multicolumn{2}{|c|}{ DENV-2 } & \multicolumn{2}{|c|}{ DENV-3 } & \multicolumn{2}{|c|}{ DENV-4 } \\
\hline & $\begin{array}{l}\text { Mean fre- } \\
\text { quency (\%) }\end{array}$ & SD & $\begin{array}{l}\text { Mean fre- } \\
\text { quency (\%) }\end{array}$ & SD & $\begin{array}{l}\text { Mean fre- } \\
\text { quency (\%) }\end{array}$ & SD & $\begin{array}{l}\text { Mean fre- } \\
\text { quency (\%) }\end{array}$ & SD \\
\hline \multicolumn{9}{|c|}{ Abundant $\left(f_{i} \geq 6\right)$} \\
\hline Leu & 9.4 & 1.6 & 9.2 & 2.3 & 9.3 & 1.5 & 9.4 & 1.3 \\
\hline Val & 6.7 & 2.5 & 6.4 & 2.3 & 6.7 & 2.5 & 6.9 & 2.1 \\
\hline Thr & 7.6 & 4.2 & 7.8 & 2.0 & 8.1 & 1.9 & 8.0 & 1.8 \\
\hline Ala & 7.0 & 2.5 & 6.7 & 2.6 & 6.9 & 2.4 & 6.4 & 1.4 \\
\hline Gly & 8.2 & 1.3 & 8.1 & 1.6 & 8.4 & 0.9 & 8.5 & 1.2 \\
\hline Lys & 6.0 & 1.9 & 6.4 & 2.7 & 6.5 & 1.1 & 6.0 & 1.7 \\
\hline Glu & 6.5 & 1.0 & 7.1 & 1.1 & 6.6 & 1.1 & 6.5 & 0.8 \\
\hline \multicolumn{9}{|c|}{ Intermediate $\left(6>f_{i} \geq 4\right)$} \\
\hline Ile & 5.9 & 2.8 & 6.5 & 2.5 & 6.0 & 2.2 & 5.9 & 2.7 \\
\hline Ser & 6.0 & 1.7 & 5.6 & 2.3 & 5.3 & 1.3 & 5.8 & 1.2 \\
\hline Pro & 4.1 & 1.1 & 4.3 & 1.3 & 4.5 & 0.8 & 4.3 & 0.8 \\
\hline Asp & 4.3 & 0.9 & 3.9 & 1.4 & 4.0 & 1.0 & 4.3 & 1.2 \\
\hline $\operatorname{Arg}$ & 5.7 & 1.5 & 5.7 & 2.4 & 5.1 & 1.9 & 5.9 & 1.5 \\
\hline \multicolumn{9}{|l|}{ Rare $\left(4>f_{i} \geq 2\right)$} \\
\hline Phe & 3.1 & 1.2 & 2.9 & 1.0 & 2.9 & 0.6 & 3.1 & 1.7 \\
\hline Met & 3.8 & 1.3 & 3.7 & 0.9 & 3.7 & 0.9 & 3.8 & 0.8 \\
\hline Tyr & 2.1 & 1.0 & 2.1 & 0.9 & 2.1 & 1.0 & 2.3 & 0.3 \\
\hline Trp & 2.8 & 0.3 & 2.6 & 0.2 & 2.8 & 0.1 & 2.7 & 0.2 \\
\hline $\mathrm{His}$ & 2.1 & 1.5 & 2.0 & 1.3 & 2.1 & 0.9 & 2.0 & 1.2 \\
\hline Asn & 3.7 & 1.4 & 4.0 & 2.7 & 4.0 & 1.5 & 3.2 & 1.2 \\
\hline Gln & 3.2 & 1.1 & 3.0 & 1.2 & 3.3 & 0.6 & 3.0 & 1.6 \\
\hline \multicolumn{9}{|c|}{ Very Rare $\left(f_{i}<2\right)$} \\
\hline Cys & 1.7 & 0.4 & 1.7 & 0.2 & 1.7 & 0.1 & 1.7 & 0.4 \\
\hline
\end{tabular}

$f_{i}$ indicates frequency of ith number of residues, where $i=1$ to 20 . 


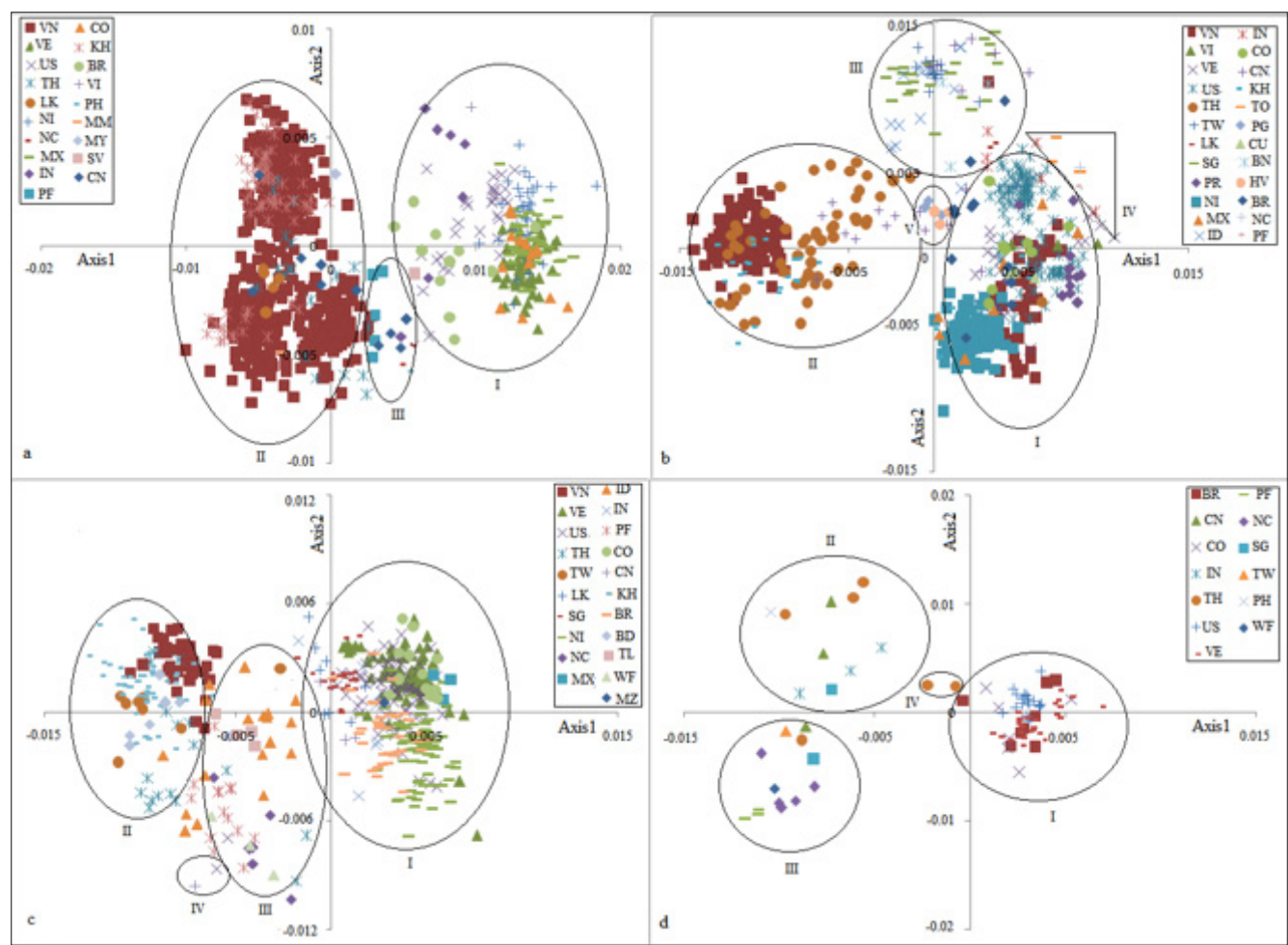

Figure 1.Position of polyprotein sequences of viral strains within principal axes generated by COA on amino acid usage, isolated from different countries in [a] DENV-1, [b] DENV-2, [c] DENV-3 and [d] DENV-4. Abbreviation of country denotes BD, Bangladesh; BR, Brazil; BN, Brunei; VI, British Virgin Island; KH, Cambodia; CN, China; CO, Colombo; CU, Cuba; TL, East Timor; SV, El Salvador; IN, India; ID, Indonesia; HV, Havard; MY, Malaysia; MX, Mexico; MZ, Mozambique; MM, Myanmar; NI, Nicaragua; NC, New Caledonia; PG, Papua New Guinea; PH, Philippines; PF, French Polynesia, PR, Puerto Rico; SG, Singapore; LK, Sri Lanka; TW, Taiwan; TO, Tongo; TH, Thailand; US, United States, VE, Venezuela; VN, Vietnam; WF, Wallis and Futuna [35]. I-V indicates cluster number

\section{Phylogenetic Analysis of Polyproteins}

In order to understand the origin of viral strains of a serotype, phylogenetic analysis on polyproteins was carried out for each serotype. Figure 2 shows the clusters, resulted from the phylogenetic analysis on polyproteins. The close scrutiny of the clusters, generated by COA on amino acid usage (Figure 1) and phylogenetic analysis of polyproteins (Figure 2 ), illustrates that the clustering pattern of the polyprotein sequences of viral strains, isolated from different countries during different time periods in each serotype, is the same in both the analyses. In DENV-1, cluster I contains viral strains isolated from the countries of America and India. Cluster II includes strains isolated from the Asian countries like Vietnam, Cambodia, Thailand, China, Sri Lanka and Myanmar. Cluster III includes most of the strains from Oceania and few from China and Philippines (Figure 1a, 2a). In DENV-2, cluster I contains most of the strains from America and few strains from countries of Southeast Asia. Cluster II includes strains from Asian countries like Vietnam, Cambodia, Thailand and China. Cluster III contains strains isolated from countries of Asia like Indonesia, Brunei, Singapore, China, Taiwan, Sri Lanka, India and Vietnam.
Cluster IV includes most strains from Oceania and other from India. Cluster V contains strains isolated from Papua New Guinea, Harvard, China and Indonesia (Figure 1b, 2b). DENV-3 has four clusters. Cluster I includes most of the strains from America and other from Mozambique, China, Taiwan, Sri Lanka, India and Singapore. Cluster II contains strains from Asian countries Vietnam, Cambodia, Thailand, China, Taiwan, Indonesia and Bangladesh. Cluster III includes most of the strains from countries of Oceania, and others from Singapore, Indonesia and Taiwan. Cluster IV consists of strains isolated from China and USA (Figure 1c, 2c). In DENV-4, cluster I contains strains from American countries. Cluster II includes strains from Asian countries like Thailand, Singapore, China, India and Philippines. Cluster III consists most of the strains isolated from Oceania, and other from China, Taiwan, Thailand and Singapore. Cluster IV contains Thailand strains isolated during 1997 (Figure 1d, 2d). The similar clustering pattern of viral strains, generated both by COA on amino acid usage and phylogenetic analysis on polyproteins, indicates that the viral strains, having same polyprotein composition, are descended from similar geographic origin in each serotype. 

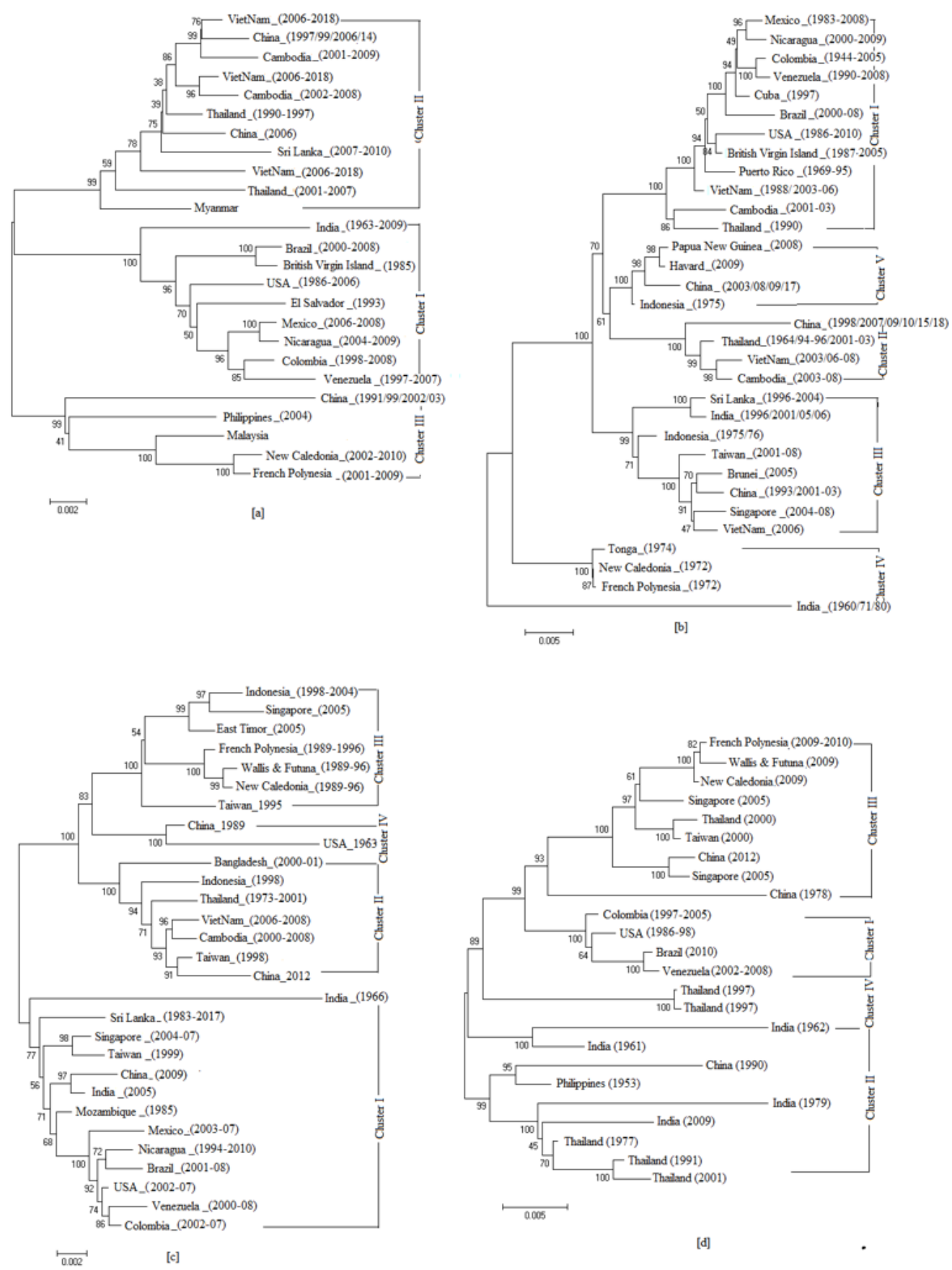

Figure 2.Phylogenetic trees of polyprotein sequences of viral strains isolated from different countries during different time periods in [a] DENV-1, [b] DENV-2, [c] DENV-3 and [d]

DENV-4. Numerals in parentheses indicate years of isolation of viral strains

\section{Polyprotein Variation and Antigenicity of Viral Strains}

To find out the source of variation, multiple sequence alignment of the polyproteins from different clusters, produced by COA/ phylogenetic analysis in each serotype, was performed. The residues having at least $1 \%$ variation at a position in aligned sequences was considered as polymorphic residues. It is found that the polymorphic residues are distributed at different positions of the polyprotein sequences and corresponds to the geographic origin of viral strains in each serotype. It is also noticed that polymorphic residues occupy some positions in linear epitopes within the structural proteins (capsid, premembrane/membrane \& envelope) and NS1 regions in each serotype. These linear epitopes were retrieved from the database of the experimental data of linear epitopes with 
BLAST search (identity $\geq 70 \%$ ) from IEDB in each dengue serotype. Table 2 represents the list of linear epitopes on the structural proteins and NS1 regions with underlined position of polymorphic residues of viral strains in each serotype. These residues are with dissimilar physicochemical properties and occupying positions accessible to the surface. Thus, these positions on epitope with polymorphic residues having with dissimilar physicochemical properties and surface accessibility might produce antigenic variation among the viral strains of different geographic origin and increases the vulnerability of disease outbreak on subsequent infection by viral strains of different geographic origin.

Table 2.List of linear epitopes and residue variations on structural proteins and NSI of viral strains in dengue serotypes

\begin{tabular}{|c|c|c|c|c|}
\hline $\begin{array}{c}\text { DENV } \\
\text { serotype }\end{array}$ & Epitopes & Location & $\begin{array}{c}\text { Polymorphic } \\
\text { residue position in } \\
\text { polyprotein }\end{array}$ & Residue variants \\
\hline \multirow{11}{*}{ DENV-1 } & QRKKT $\underline{\text { GKPI }}$ & Capsid & 9,10 & $\mathrm{G} / \mathrm{A}, \mathrm{K} / \mathrm{Q}$ \\
\hline & DSRCPTQGEATLVEEEQDANF & Envelope & 363 & $\mathrm{~V} / \mathrm{M}$ \\
\hline & ITEHGTIAI & Envelope & 435,443 & $T / S, T / I$ \\
\hline & P吕EIQLTDY & Envelope & 450,451 & $\mathrm{~T} / \mathrm{S}, \mathrm{S} / \mathrm{T}$ \\
\hline & WTSGASTSQE & Envelope & 502,505 & $\mathrm{~S} / \mathrm{T}, \mathrm{S} / \mathrm{T} / \mathrm{L}$ \\
\hline & ETEPPFGESY & Envelope & 649 & T/A \\
\hline & LAQGKKMIKPQPMEHKYS & NS1 & $672,678,686,687$ & $\begin{array}{c}\mathrm{A} / \mathrm{T} / \mathrm{G}, \mathrm{M} / \mathrm{S} / \mathrm{T} \\
\mathrm{H} / \mathrm{Y}, \mathrm{K} / \mathrm{R}\end{array}$ \\
\hline & DTPECPDEQR & NS1 & 914,919 & $\mathrm{D} / \mathrm{N}, \mathrm{P} / \mathrm{S}$ \\
\hline & GGPISQHN $\underline{Y}$ & NS1 & 1026,1031 & $\mathrm{I} / \mathrm{M}, \mathrm{Y} / \mathrm{H}$ \\
\hline & GYFTQIAGPW & NS1 & 1039 & $\mathrm{~T} / \mathrm{A}$ \\
\hline & EGTTVVVDEE & NS1 & 1065 & $\mathrm{H}, \mathrm{N}$ \\
\hline \multirow{13}{*}{ DENV-2 } & RKKARSTPFN & Capsid & 9,10 & $\mathrm{R} / \mathrm{K}, \mathrm{S} / \mathrm{N}$ \\
\hline & CITTGEHRR & Membrane & $195,196,200$ & $T / A ; T / A ; H / R$ \\
\hline & AKQPPATLR & Envelope & 332,333 & $\mathrm{Q} / \mathrm{H}, \mathrm{P} / \mathrm{S}$ \\
\hline & ESRCPTQGEPSILNEEQDKRF & Envelope & $351,361,363$ & $E / A, S / T, N / K$ \\
\hline & GKVVQPPEN & Envelope & 409,411 & $\mathrm{~V} / \mathrm{I}, \mathrm{Q} / \mathrm{L}$ \\
\hline & TPHSGEE$\underline{H} A V G N D T G K H G K E \underline{I}$ IIIPQSSIITE & Envelope & $429,442,444,450$ & $\mathrm{H} / \mathrm{N}, \mathrm{I} / \mathrm{V}, \mathrm{I} / \mathrm{V}, \mathrm{I} / \mathrm{T}$ \\
\hline & DTQGSNWIQK & Envelope & 506,508 & $\mathrm{~T} / \mathrm{K}, \mathrm{G} / \mathrm{E}$ \\
\hline & VIIEKDSPVNIEAEPPFG & Envelope & 822 & $\mathrm{I} / \mathrm{T}$ \\
\hline & KRㅗLㄹPQPT & NS1 & 878,880 & $S / Y / F, R / K$ \\
\hline & RPQPTELL $\underline{Y}$ & NS1 & 880,887 & $\mathrm{R} / \mathrm{K}, \mathrm{K} / \mathrm{R}$ \\
\hline & AECPNINRAW & NS1 & 921 & T/A \\
\hline & $\underline{F A G P V S Q H N \underline{Y}}$ & NS1 & 1122,1131 & $\mathrm{~F} / \mathrm{L}, \mathrm{Y} / \mathrm{N}$ \\
\hline & GY $\underline{\text { HTQTAGPW }}$ & NS1 & 1136,1139 & $H / Y, T / I$ \\
\hline \multirow{7}{*}{ DENV-3 } & ITNIITTDSR & Envelope & 348 & $\mathrm{I} / \mathrm{V}$ \\
\hline & TQGEAILPEEQDQNY & Envelope & 361 & $\mathrm{I} / \mathrm{V} / \mathrm{T} / \mathrm{A}$ \\
\hline & GNDTQGVTVEEITPQAST므 & Envelope & $434,440,449$ & $D / E, A / V, T / V$ \\
\hline & LPWISGATT & Envelope & 499 & T/A \\
\hline & QNSGGTSIF & Envelope & 550 & $\mathrm{~N} / \mathrm{T}$ \\
\hline & GEDAPCKIPF & Envelope & 609 & $\mathrm{~A} / \mathrm{V}$ \\
\hline & IPFSTEDGQG & Envelope & 620 & G/E \\
\hline
\end{tabular}




\begin{tabular}{|c|c|c|c|c|}
\hline & ANPVVVTKKEEPVNIEA & Envelope & 635 & $\mathrm{~V} / \mathrm{I}$ \\
\hline & AKIVTAETQNSSFIII & NS1 & 901 & $T / \mathrm{I}$ \\
\hline & 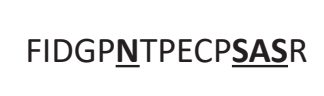 & NS1 & $912,918-920$ & $\begin{array}{c}\mathrm{N} / \mathrm{S}, \mathrm{S} / \mathrm{N}, \mathrm{A} / \mathrm{T} / \mathrm{V} \\
\mathrm{S} / \mathrm{L}\end{array}$ \\
\hline & SQHENHRPGY & NS1 & 1027 & $H / Y$ \\
\hline \multirow{14}{*}{ DENV-4 } & ERNRV $\underline{\mathbf{S} T P Q G}$ & Capsid & 23 & $\mathrm{~S} / \mathrm{P}$ \\
\hline & $\underline{\text { TSNHGVTAII }}$ & Envelope & $434,435,442$ & $\mathrm{~T} / \mathrm{I}, \mathrm{S} / \mathrm{P}, \mathrm{T} / \mathrm{M}$ \\
\hline & SPSVEV $\underline{K} L P D$ & Envelope & 453 & $\mathrm{~K} / \mathrm{E}$ \\
\hline & LPLPWITGAD & Envelope & 500,501 & $\mathrm{~T} / \mathrm{S} / \mathrm{A}, \mathrm{T} / \mathrm{A}$ \\
\hline & $\underline{\text { TGADTSEEVHWW }}$ & Envelope & $501,506,509$ & $T / A, S / L, H / Q$ \\
\hline & KVKYEGAGA & Envelope & 608 & $\mathrm{~A} / \mathrm{T}$ \\
\hline & PLAAENTNSV & Envelope & 636,639 & $L / F, N / H / Y$ \\
\hline & KFQPESPAR & Envelope & 807 & $\mathrm{~K} / \mathrm{Q}$ \\
\hline & 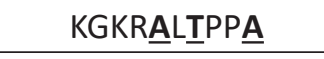 & NS1 & $877,879,882$ & $\mathrm{~A} / \mathrm{V}, \mathrm{T} / \mathrm{A}, \mathrm{A} / \mathrm{V}$ \\
\hline & PPASDLKYW & NS1 & 882,883 & $\mathrm{~A} / \mathrm{V} ; \mathrm{S} / \mathrm{N}$ \\
\hline & TPEARNSTF & NS1 & 902,903 & $\mathrm{~A} / \mathrm{T}, \mathrm{R} / \mathrm{K}$ \\
\hline & IDGPDTSECPNEERA & NS1 & 909,920 & $\mathrm{I} / \mathrm{V}, \mathrm{E} / \mathrm{G}$ \\
\hline & IPKSYAGPE & NS1 & 1020,1025 & $S / A, F / S / I$ \\
\hline & YATQTVGPW & NS1 & 1039 & $\mathrm{~V} / \mathrm{A} / \mathrm{M}$ \\
\hline
\end{tabular}

\section{Conclusion}

In summary, the intra-serotype comparative study of polyproteins of dengue virus reveals that the residues like Val, Thr, Ala, Gly, Lys, and Glu are abundant in the polyproteins of viral strains in each serotype. Polyprotein composition of viral strains in each dengue serotype varies according to its geographical origin. These compositional variations occur due to the presence of polymorphic residues at different positions along the polyprotein sequences of viral strains. Furthermore, polymorphic residues occur on the linear epitopes of structural proteins (capsid, pre-membrane/ membrane, and envelope) and NS1 regions. These residues are with dissimilar physicochemical properties and occupy surface accessible positions. These polymorphic residue positions on the epitopes might act as putative sites for generation of antigenic variation among viral strains of a serotype of different geographical origin. This might increase the chance of antibody-dependent enhancement of the disease on secondary infection with a heterotypic intra-serotype viral strain of different geographic origin. Therefore, these residue positions may be considered as putative target for development of drugs or vaccine, in future.

\section{Acknowledgement}

The authors acknowledge the support of Department of Zoology, S.A. Jaipuria College, Kolkata, India and Centre for Bioinformatics, Pondicherry University, Pondicherry, India for providing the infrastructural facilities. This study was funded by University Grants Commission (Grant number: PSW-071/14-15 (ERO)), Government of India, New Delhi, India.

\section{Funding}

This study was supported by University Grants Commission (Grant number: PSW-071/14-15 (ERO)), Government of India, New Delhi, India.

\section{Authors' Contributions}

IC conceived the study, performed the research work, analysed the data and contributed to write the paper. AP critically reviewed the analysis of data and contributed to write the paper. PG contributed to the research work.

\section{Conflicts of Interest: None \\ References}

1. Tang $\mathrm{T}$, Rodpradit $\mathrm{P}$, Chinnawirotpisan $\mathrm{P}$ et al. Comparative analysis of full-length genomic sequences of 10 Dengue serotype 1 viruses associated with different genotypes, epidemics, and disease severity isolated in Thailand over 22 Years. Am J Trop Med Hyg 2010; 83: 1156-65.

2. Lara-Ramírez EE, Salazar MI, López-López Mde J et al. Large-scale genomic analysis of codon usage in Dengue virus and evaluation of its phylogenetic dependence. Biomed Res Int 2014.

3. Endy TP, Weaver SC, Hanley KA. Dengue virus: past, 
present and future. In: Hanley KA and Weaver SC (eds) Frontiers in Dengue Virus Research, Caister Academic Press, Norfolk, UK. 2010.

4. Behura SK, Severson DW. Nucleotide substitutions in dengue virus serotypes from Asian and American countries: insights into intra codon recombination and purifying selection. BMC Microbiol 2013; 14: 37.

5. World Health Organization. Dengue/dengue hemorrhagic fever. Fact sheet no. 117. 2002. Available from: http://www.who.int/mediacentre/factsheets/ fs117/en/index.html. Accessed 27 December 2006.

6. Smith $\mathrm{SA}$, de Alwis $\mathrm{AR}$, Kose $\mathrm{N}$ et al. Isolation of dengue virus-specific memory $B$ cells with live virus antigen from human subjects following natural infection reveals the presence of diverse novel functional groups of antibody clones. J Virol 2014; 88: 12233-41.

7. Rico-Hesse R. Molecular evolution and distribution of dengue viruses type 1 and 2 in nature. Virology 1990; 174: 479-493.

8. Zaki A, Perera D, Jahan SS et al. Phylogeny of dengue viruses circulating in Jeddah, Saudi Arabia: 1994 to 2006. Trop Med In. Health 2008; 13: 584-592.

9. Aquino $\mathrm{VH}$, Amarilla AA, Alfonso HL. New genotype of dengue type 3 virus circulating in Brazil and Colombia showed a close relationship to old Asian viruses. PLOS One 2009; 4: e7299.

10. Bedi SK, Prasad A, Mathur K. Positive selection and evolution of dengue type- 3 virus in the Indian subcontinent. J Vector Borne Dis 2013; 50: 188-96.

11. Weaver SC, Vasilakis N. Molecular evolution of Dengue viruses: contributions of phylogenetics to understanding the history and epidemiology of the preeminent arboviral disease. Infect Genet Evol 2009; 9: 523-40.

12. Greenacre M. Theory and Application of Correspondence Analysis, Academic Press, London. 1994.

13. Peden JF. Analysis of codon usage. Thesis, University of Nottingham. 1999.

14. Thompson JD, Higgins DG, Gibson TJ. CLUSTAL W: improving the sensitivity of progressive multiple sequence alignment through sequence weighting, position-specific gap penalties and weight matrix choice. Nucleic Acids Res 1994; 22: 4673-80.

15. Tamura K, Dudley J, Nei M et al. MEGA4: Molecular Evolutionary Genetics Analysis (MEGA) Software Version 4.0. Mol Biol Evol 2007; 24: 1596-9.

16. Kassam S, Meyer P, Cornfield AP, et al. Single Nucleotide Polymorphisms (SNPs): history, biotechnological outlook and practical applications. Current Pharmacogenomics 2005; 3: 237-45.

17. Su ZD, Sun L, Xu DX et al. Quantitative detection of single amino acid polymorphisms by targeted proteomics. Journal of Molecular Cell Biology 2011; 3: 309-15.
18. Larsen JKP, Lund O, Nielsen M. Improved method for predicting linear B-cell epitopes. Immunome Research 2006; $2: 2$.

19. Emini EA, Hughes JV, Perlow DS et al. Induction of hepatitis $A$ virus-neutralizing antibody by a virusspecific synthetic peptide. J Virol 1985; 55: 836-9.

20. Wong SS, Abd-Jamil J, Abubakar S. Antibody neutralization and viral virulence in recurring dengue virus type 2 outbreaks. Viral Immunology 2007; 20: 359-368.

21. Lin SR, Zou G, Hsieh SC. The helical domains of the stem region of dengue virus envelope protein are involved in both virus assembly and entry. J Virol 2011; 85: 5159-71.

22. Erb ST. PhD Thesis Department of Microbiology, Immunology and Pathology. Colorado State University, USA. 2011. 